Título artículo / Títol article:

\title{
A framework for work-based learning: basic pillars and the interactions between them
}

Autores / Autors

Ferrández Berrueco, María Reina ; Kekale, Tauno ; Devins, David

Revista:

Higher Education, Skills and Work-Based Learning

Versión / Versió:

Postprint

Cita bibliográfica / Cita bibliogràfica (ISO 690):

FERRANDEZ, Reina; KEKALE, Tauno; DEVINS, David. A framework for work-based learning: Basic pillars and the interactions between them. Higher Education, Skills and Work-Based Learning, 2016, vol. 6, no 1.

url Repositori UJI:

http://hdl.handle.net/10234/149307 


\title{
A Framework for Work-Based Learning: Basic Pillars and the Interactions between them
}

\author{
Ferrández-Berrueco, Reina (Universitat Jaume I, SP) \\ Kekäle, Tauno (Vaasan Ammattikorkeakoulu, FI) \\ Devins, David (LeedsBeckett University. UK)
}

\begin{abstract}
:
Purpose: European policy is placing an increasing emphasis on involving employers and labour market institutions in the design and delivery of higher education programmes that match curricula to current and future needs of the economy. The aim of this paper is to investigate the curriculum development process for work-based learning (WBL) programmes and to connect it to the basic pillars, organizational and pedagogical strategies and key stages that enable higher education institutions to foster students' learning, employability and innovation.
\end{abstract}

Design/methodology/approach: Case studies of 14 European WBL programmes in Higher Education are reported using interviews and document analysis. These case studies are used to develop a final framework and examples of practice.

Findings: A framework was designed to develop WBL programmes that include three basic pillars and the interactions between them to enhance learning quality (Doctrine), provide authentic experiences (Authenticity) and respect the ways of developing and delivering WBL (Culture).

Research limitations/implications: While selecting the cases on this 'best practices' basis, some important pitfalls were not discussed. Thus, rather than offering a definitive theory, we provide a framework of issues that should at least be taken into account in the different stages of planning, delivery and reflection.

Originality/value: The research presents 14 case studies from programmes recognized in 6 European countries and develops an original WBL programme planning, delivery and evaluation framework that can also be used as a checklist for HEIs offering workbased learning programmes.

Keywords: work-based learning; higher education, curriculum development, student's learning, market needs, organizational practice.

Paper type; Research paper

\section{Introduction}

The development of partnerships between Higher Education Institutions (HEIs) and employers is seen as a critical factor in identifying learning requirements (Bruges 
Communiqué, 2010; Bucharest Communiqué, 2012), improving the relevance of education, and facilitating access to education and learning. In this context, curricula should involve employers and labour institutions, and must respond quickly to the changing needs of the economy. The problem with implementing such work-based learning (WBL) is that higher education systems have generally been slow to adapt their activities, and particularly their curricula, to these changes (EC, 2012). In addition there is, in some cases, strong resistance to changing the traditional university curricula based on massification and "pure contents" (Nowotny et al. 2001) into more flexible and individual curricula based on labour experience. The benefits of work-based learning for students are clear, and are recognized in all the European guidelines. However, the benefits for organizations and society (Cedefop, 2013) are not as obvious in the short term as they may become in the medium to long term. Moreover, this work-based learning is only possible if the world of work and academia join forces. A wide range of terms is used to refer to the concept of work-based learning across Europe. Some of these terms are: internships, work integrated learning, workplace learning, work-related learning, vocational learning, flexible learning and problem solving or simulations. This often leads to conceptual ambiguity, as each concept is open to multiple and different interpretations.

Based on the results of the WBLIC project funded by the Erasmus LLP programme (518586-LLP-1-2011-1-UK-ERASMUS-ECUE), this paper draws on 14 case studies to inform the construction of a framework that, by highlighting student learning (Brennan and Little, 1996), will be useful for higher-education institutions and their stakeholders in planning work-based learning programmes.

We start with the classic development cycle as a way to describe the planning and delivery of the curriculum and programme (Contreras, 1991). This framework has developed from a logical organizational perspective centred on the labour market and employability. The aim of this article is to provide another perspective, developing a new parallel framework - with the student's learning at the centre (Brennan and Little, 1996, Raelin, 2008) - as a way to distinguish a simple organizational practice from a good practice.

For the purposes of this article, we use a definition of WBL adapted from Garnett (2005): [work-based learning] is a learning process which focuses university level thinking upon work (paid or unpaid) in order to facilitate the recognition, acquisition and application of individual and collective knowledge, skills and abilities to achieve specific accredited outcomes of significance to the learner, their employer and the university.

The following sections highlight the different strategies described in the cases, collated to facilitate all the elements Garnett raises, and paying special attention to those related to students' learning opportunities, which is the main goal of this paper.

\section{Initial framework}

The initial framework considered to develop a new WBL programme should contain all the stages of the typical education programme development cycle, namely, planning, designing, delivering and evaluation. 
However, as this paper concerns WBL we will highlight understanding of the market needs separately from the planning stage, as this need should be the essential driver behind a WBL programme (Fig. 1).

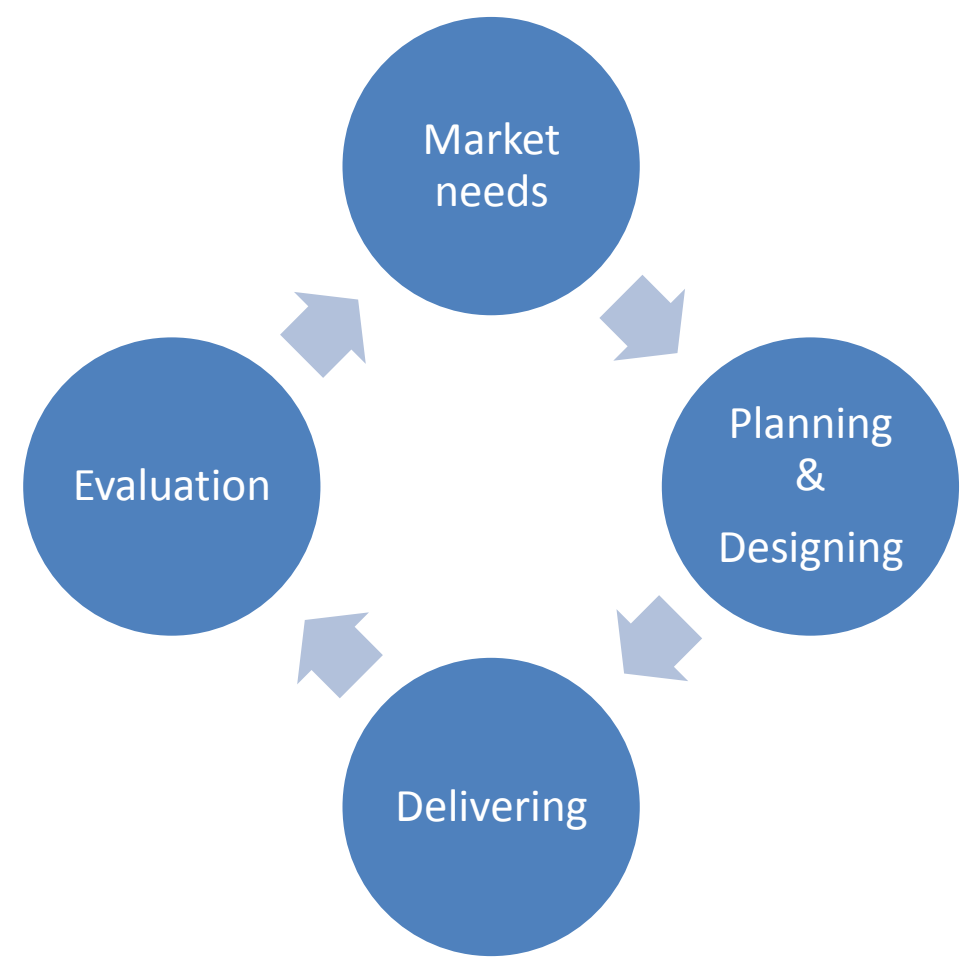

Figure 1: Conceptual Framework: Developing a WBL Programme

\section{Case study methodology}

The applied nature of the study influenced the design of the research methodology. In this study we adopted a pragmatic research approach (Tranfield and Starkey 1998) following practitioners' or policy makers' agendas, in contrast to 'pure' areas where research is largely dictated by the linear and logical development of an academic agenda. The strengths of this approach include its ability to further understanding of the nature of the problem and triangulate data (Creswell 2003), as well as providing an insight into 'what works' (Patton 1990). These were key factors in the selection of this approach.

A case study approach (Glatthorn 1985) was chosen to develop a rich picture of programme development in HEIs in Austria, the Czech Republic, Finland, Germany, Poland, Spain and the UK. A range of stakeholders including students, employers, teaching staff, programme leaders, administrators, HEI strategic planners and labour market intermediary organizations contributed to the data collection underpinning the case studies. A common semi-structured discussion guide to collect data was designed and agreed with researchers in each European state. This discussion guide was based on the Deming's (PDCA; 1982) cycle for curriculum development, which envisaged four phases progressing from the identification of labour market need, through planning and delivery, to evaluation of the curriculum. This is one of the most widely adopted 
frameworks for describing an educational programme (Contreras, 1991), and it has been used in other similar studies (Whittington and Ferrández-Berrueco, 2007). Although the model implies a linear process, in practice the phases are interconnected and often iterative. The key differentiating factor associated with WBLIC is the extent to which employers influence the development and delivery of the curriculum throughout the cycle.

Interviews for the case studies were conducted with at least one interviewee from each stakeholder group, and potentially several from some groups (such as students and employers) when some contradictions or additional points should be clarified. Of course, it is a research limitation but if arguments in the triangulation process were iterative and no new information was added we considered it was reliable enough. The discussion guides were designed to be used flexibly and the duration of interviews ranged from under an hour to almost two hours. Interviews were recorded digitally and a summary of the key issues from each interview was written up in English. In addition to primary data collection, the case studies collected relevant secondary data (e.g., curricula design guidelines, course specifications) and drew on other secondary sources to inform the development of the case studies as appropriate. Each case study was written up in a common format (typically between 3,000 and 4,000 words in length).

Comparisons are possible following the two basic case study methodologies (Caïs, 1997): case comparison (longitudinal), and variables (stages of the cycle) comparison (crosscases). The first methodology illustrates the "natural story" of the programme, enabling an understanding of the decisions taken within its own context. The second allows us to compare the cases in terms of the key differentiating factors associated with WBLIC. In this study we have used both methodologies; we focus on the provision of learning opportunities and the organizational strategies that illustrate this provision. To do this, we build a new framework to facilitate the data analysis. However, it must be taken into account that the main goal of this article is not to compare the practices, but to contrast them with what the literature identifies as good practices.

\section{The cases}

The university systems in the countries selected naturally differ in some aspects. Given that the UK has a much longer history of WBL than the other case countries, it comes as little surprise that the largest number and the most elaborate WBL arrangements can be found there, followed by examples from Germany (where 'work-integrated learning' seems to be the most widely used term). In the other countries, however, examples of WBL in higher education tend to be fairly scarce. Austria, Germany and Finland have a dual university system: some follow a more traditional orientation and others are more vocationally oriented (Universities of Applied Sciences, Fachhochschulen). In the latter system, work-based learning is a fairly widespread practice, and the traditional universities are picking up some of their models.

Spain's universities are on the whole traditional, although some smaller universities link university and vocational programmes. Work-based learning in Spain refers almost 
exclusively to work placements. Spanish universities increasingly incorporate work placements into their curricula.

As a former communist country, the Czech Republic has a history of strong ties between the universities and industry; this cooperation was abandoned at the end of the Communist era, however. Work-based learning (through placements) in undergraduate (Bachelor) courses is mainly restricted by funding; it is considered to be expensive and is therefore mainly provided at Master degree level. A new higher education law, currently being prepared, is expected to promote the division of HEI into research and non-research universities, and to increase the involvement of companies in university education (e.g., through mandatory work placements). Likewise, Poland has a history of strong ties between the universities and industry, but again, this cooperation came to an end with the demise of the Communist era. In recent years however, attempts have been made to improve cooperation between HE and the labour market, such as through partnerships between HEIs and employers. However, these partnerships need to be made more sustainable and systematic. Polish HEIs are currently fairly unfamiliar with the use of work-based learning to develop professional skills.

Thus, we have four distinct groups of countries with different WBL orientations. In the UK, WBL has been debated and practised for decades. Germanic countries (Germany and Austria in our cases) - and for the last 15 years also Finland - run a dual HE system with a traditional and a more WBL-oriented "Applied Science" university structure. The communist countries previously had very practically oriented, specialized universities (e.g., railway universities, mining universities, agricultural universities, and so on) but the connection between work and academic learning was mostly dissolved in the 1990s and early 2000s and is only now slowly being restructured. Finally, the discussion is starting and the early stages of implementation are being tested in Southern-European countries, such as Spain, where the traditional university still seems to exist in its purest form.

\begin{tabular}{|l|l|l|l|}
\hline Country & Course/Qualification & Institution & $\begin{array}{l}\text { Work based } \\
\text { element }\end{array}$ \\
\hline \multirow{4}{*}{ Austria } & $\begin{array}{l}\text { BSc Mechatronics and } \\
\text { Management }\end{array}$ & $\begin{array}{l}\text { University of Applied } \\
\text { Science, Upper } \\
\text { Austria }\end{array}$ & $\begin{array}{l}\text { Subject overarching } \\
\text { project and thesis }\end{array}$ \\
\cline { 2 - 4 } & BA Social Work & $\begin{array}{l}\text { University of Applied } \\
\text { Science, Vienna }\end{array}$ & $\begin{array}{l}\text { Practicums in years } \\
1,2 \text { and 3 (20 weeks } \\
\text { in total) }\end{array}$ \\
\cline { 2 - 4 } & $\begin{array}{l}\text { Production Technology } \\
\text { and Organization } \\
\text { (Bachelor) }\end{array}$ & $\begin{array}{l}\text { FH Joanneum } \\
\text { University of Applied } \\
\text { Science }\end{array}$ & $\begin{array}{l}\text { Three-month block } \\
\text { of lectures followed } \\
\text { by three months with } \\
\text { an employer. This } \\
\text { rotation continues }\end{array}$ \\
\hline
\end{tabular}




\begin{tabular}{|c|c|c|c|}
\hline & & & $\begin{array}{l}\text { throughout the four- } \\
\text { year programme }\end{array}$ \\
\hline \multirow[t]{2}{*}{$\begin{array}{l}\text { Czech } \\
\text { Republic }\end{array}$} & $\begin{array}{l}\text { PG Diploma/Masters in } \\
\text { Modern Railway } \\
\text { Vehicles }\end{array}$ & $\begin{array}{l}\text { Czech Technical } \\
\text { University in Prague }\end{array}$ & $\begin{array}{l}\text { Involvement of } \\
\text { employers in } \\
\text { practical projects, } \\
\text { lectures, and short- } \\
\text { term practical } \\
\text { training }\end{array}$ \\
\hline & $\begin{array}{l}\text { Masters in Mechanical } \\
\text { Engineering with } \\
\text { specialization in } \\
\text { management and } \\
\text { economics of enterprise } \\
\text { - }\end{array}$ & $\begin{array}{l}\text { Czech Technical } \\
\text { University in Prague }\end{array}$ & $\begin{array}{l}\text { Lectures given by } \\
\text { managers of } \\
\text { companies, reflexive } \\
\text { project work and } \\
\text { learning }\end{array}$ \\
\hline \multirow[t]{3}{*}{ England } & $\begin{array}{l}\text { Masters in Strategic } \\
\text { Communication }\end{array}$ & $\begin{array}{l}\text { Leeds Metropolitan } \\
\text { University }\end{array}$ & $\begin{array}{l}\text { Majority of the } \\
\text { learning undertaken } \\
\text { through reflexive } \\
\text { project work }\end{array}$ \\
\hline & $\begin{array}{l}\text { BA Business } \\
\text { Leadership and } \\
\text { Corporate Management }\end{array}$ & $\begin{array}{l}\text { Northumbria } \\
\text { University }\end{array}$ & $\begin{array}{l}\text { Year } 1 \text { in HEI, years } \\
2 \text { and } 3 \text { largely at } \\
\text { work }\end{array}$ \\
\hline & $\begin{array}{l}\text { Work Based Integrative } \\
\text { Studies (variety of } \\
\text { levels) }\end{array}$ & University of Chester & $\begin{array}{l}\text { Mostly at work, } \\
\text { reflexive learning }\end{array}$ \\
\hline Finland & $\begin{array}{l}\text { Company Clinic } \\
\text { (variety of levels) }\end{array}$ & $\begin{array}{l}\text { Vaasa University of } \\
\text { Applied Sciences }\end{array}$ & $\begin{array}{l}\text { Research and } \\
\text { development project } \\
\text { (variable up to } 50 \% \\
\text { of a programme) }\end{array}$ \\
\hline Germany & $\begin{array}{l}\text { Prozesstechnik } \\
\text { (Bachelor) }\end{array}$ & $\begin{array}{l}\text { University of Applied } \\
\text { Science, Aachen }\end{array}$ & Variable \\
\hline Poland & $\begin{array}{l}\text { BA Applied } \\
\text { Informatics }\end{array}$ & $\begin{array}{l}\text { Cracow University of } \\
\text { Economics (CUE) }\end{array}$ & $\begin{array}{l}\text { Placement of } 120 \\
\text { hours. } 15 \mathrm{hr} / \text { week } \\
\text { probation in } \\
\text { companies for best } \\
\text { graduates }\end{array}$ \\
\hline \multirow[t]{2}{*}{ Spain } & $\begin{array}{l}\text { Industrial Engineering } \\
\text { in Processes and } \\
\text { Products } \\
\text { (undergraduate) }\end{array}$ & $\begin{array}{l}\text { IMH/Universidad del } \\
\text { Pais Vasco }\end{array}$ & $\begin{array}{l}\text { Company } \\
\text { placements in years } \\
1,2 \text { and } 3\end{array}$ \\
\hline & $\begin{array}{l}\text { Innovation and } \\
\text { Development of }\end{array}$ & $\begin{array}{l}\text { Florida Universitaria } \\
\text { (Universitat de } \\
\text { Valencia) }\end{array}$ & $\begin{array}{l}\text { Project based up to } \\
375 \text { hours }\end{array}$ \\
\hline
\end{tabular}




\begin{tabular}{|l|l|l|l|}
\hline & $\begin{array}{l}\text { Business Project } \\
\text { (Master) }\end{array}$ & \\
\hline
\end{tabular}

As illustrated in the table above, the case studies reflect a range of programmes across a variety of disciplines, at different levels, on WBL elements that vary in timing, nature and intensity (some of these cases are briefly described in Ferrández-Berrueco and Kekäle, 2014). Some universities have developed a strategic approach to the management and development of WBL programmes at the institutional level. This approach is illustrated by the Work-Based Integrative Studies Programme developed at the University of Chester, in the UK, where the curriculum development process is based on pre-validated module templates and a streamlined validation process for bespoke modules commissioned and designed on a collaborative basis by employers and learners working in partnership with the university. In more traditional programmes, the majority of WBL elements involve at least one period of placement for the student, although the duration and location may vary considerably. For example the Production Technology and Organization Programme in Austria draws on the cooperative model pioneered in the United States and is based on alternating periods of three months in work and three months in the classroom in the first two years and then six months in work and in the classroom for the remaining time. Originally stimulated by the interest in interactions between an academic and a major local employer, the programme now includes a range of large and small employers in the region. Placement periods on the Bachelor's degree of Industrial Engineering in Spain are typically three days in the company and two days on campus, although once a month the student spends three days in the classroom and two days in the company to reflect a shift in emphasis towards theory. The final year of the programme includes a twelve-week placement in a company outside Spain. In some of the case study programmes, the Masters in Strategic Communication for example, the students are full time employees of a very large organization and university attendance is infrequent. This programme is based on a curriculum negotiated between the employee (learner), the employer and the university and is a dynamic form of university-based WBL provision (Willis and McKie, 2011).

These examples illustrate the diversity of practice and only scratch the surface of the richness of WBL curricula. Many programmes have an element of Recognition of Prior Learning, use a variety of forms of delivery, involve non-traditional teaching staff and follow different assessment procedures. This diversity presents a significant challenge to the development of an overarching framework to embrace the wide range of WBL and programme characteristics.

The concept of intellectual capital (Stewart 1997) has been used previously by researchers exploring the development and delivery of WBL in Higher Education (HE). For example, based on the experiences of two organizations, Garnett et al. (2008) found that effective provision of WBL within HE involves a number of structural and human capital issues 
that are essential to the effective delivery of this type of provision. We have drawn on this approach and added a further dimension, relationship capital, to reflect the key role that employers and other external stakeholders in the economy play in the development of WBL. In this article we develop the analysis and draw on the case studies from Europe to highlight the key role that the interactions between the elements of institutional capital play in the successful development and delivery of WBL.

\section{The Basic Pillars}

The initial framework based on the curriculum development cycle does not seem to be sufficient to guarantee that a WBL programme will maximize the learning opportunities in terms of Garnett's (2005) significant learning outcomes. How, then, can we decide whether a practice can be deemed good practice or not? Is any practice valid simply if it is developed in a workplace, or if it is designed by employers and academics? We could not be sure what a good practice is unless there was a proof or evidence that guaranteed that a practice enhanced learning opportunities for students. It is on this point that we need to go deeper into this initial framework to learn which basic elements are contained in each stage.

A brief definition of each of the initial stages in the cycle reveals that at least one of the following elements acts as basic pillar in Garnett's (2005) definition of WBL: Participating organizations, Programme structure, and People involved.

Hence, the market need stage deals with the external organizations' labour force demands. The planning and design stages are related to the relationship between the internal (HEI) and external participating organizations in order to develop an integrated programme. Delivering and evaluation always refer to the programme and they are carried out by all the agents (people) involved in the programme.

The balance between these pillars is in fact what builds the programme, assuring that all the requirements defined by Garnett et al. are taken into account and, therefore, they are also responsible for facilitating learning. Thus, the WBL development cycle must leverage these three pillars in order to maximize the interaction among them, so that students' learning can also be maximized (Fig.2). 


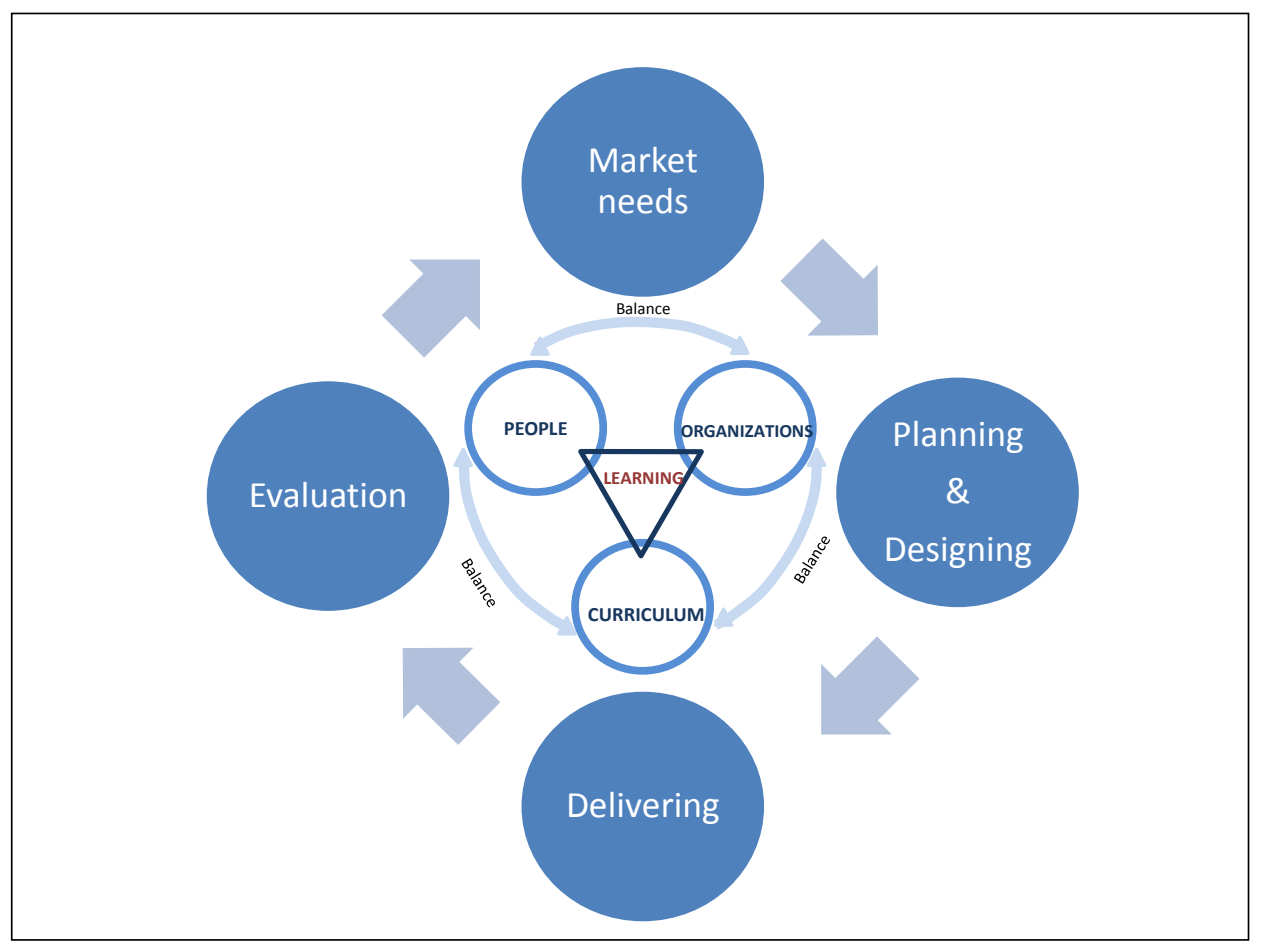

\section{Figure 2: Conceptual Framework and the Basic Pillars}

The next sections explain these key elements as a way to help programme developers to organize WBL programme practices and decide whether they are actually good practices for WBL.

As mentioned above, the decisions taken regarding the basic pillars will produce specific interactions. The main goal of a programme development team should be to maximize these interactions, because learning depends on them.

The three basic pillars are intrinsic to developing any HEI programme based on WBL principles.

\section{Participating organizations}

Two main types of organizations are involved in Work Based Learning. Their interaction and the quality of their relationship are essential in building a WBL programme (Whittington and Ferrández-Berrueco, 2007).

The key agent of WBL, the External Company/Enterprise, is what distinguishes a traditional programme from a work-based programme. It is where the learning content must be based. They cannot operate as autonomous hosts, however; they are just one of the agents of the tripartite relationship of student, HEI and employer (McEwen et al. 2010 p.64). Without this relationship, there can be no integration. The Higher Education Institution is the coordinator of the work-based learning. It is responsible for ensuring that the programme functions well, and for awarding qualifications. In the final instance, it is responsible for guaranteeing the standards and facilitating learning. According to Billet, "HEIs can provide access to a range of conceptual bases, premises for procedures 
and access to norms associated with a particular occupation. Moreover, academic settings can provide experiences in which to reflect upon this knowledge, and what is experienced in other settings, such as those where practice is conducted" (Billet, 2009, p.838).

The cases report different examples of how this relationship is established and who takes the initiative. In the cases of the Strategic Communications Master in the UK and the Modern Railway Vehicles Master in the Czech Republic, the external organization initiated the relationship, while in most other cases, it was the HEI.

At the same time, the cases also show different levels of company involvement ranging from a simple interaction in which the company's role is solely as a guest, with no involvement in the curriculum design, to total integration in which companies and HEI work side by side. These different levels of involvement cannot always be attributed to contextual issues such as regulations or flexibility, and may be due to the traditions and practices of the HEIs.

For example, the Spanish cases provide an illustration of companies taking part in the universities' Social Councils. As a member of this Council their responsibility is to evaluate and approve the programmes, but they are not often involved in the design aspect, which is usually carried out by university academic staff. This situation led to the following comment from one council member, "So we don't feel really represented in the study programmes we are approving”. Nevertheless, both Spanish cases come from consortiums or foundations where universities and companies are part of the same body.

\section{Programme structure}

The second basic pillar of the framework is the programme structure. Here, we are dealing with a special kind of programme in which interaction with the real world is key. Hence, simulations, case studies, real practices that take place in a specific period of the education process (integrally or as part of a module) are the kind of activities required. In other words, they are part of the programme, so these real practices, either inside or outside the classroom, must be integrated with the theory. This is also a distinctive feature of a WBL programme. A traditional programme does not need to leave the classroom or the HEI. But, in the words of Billet, "there is a need to guard against these provisions only reproducing occupational capacities [Garnett's "university level thinking"], important though these are, and failing to develop the kinds of critical capacities that are required for professional practice" (Billet, 2009 p. 828). The practice must enable learners to take on appropriate roles in the work place in order to learn and apply skills they have learned on the programme (Burke et al. 2009, p.15). On the other hand, there are also learning activities outside work that contain theory that is selected on the basis of the work context, and that prepare people for work (Burke et al. 2009, p.27).

Related to this point, it should be noted that all the cases reported in this paper correspond to programmes in which WBL was not an established practice. Teaching training and health science courses have traditionally used WLB and were therefore not included in 
the project as they were assumed to be aware of the importance of WBL. Part of the intention of the WBLIC project was to promote WBL in areas where this integration does not have such an established tradition. The project was particularly interested in examples where valid skills and abilities for employers were integrated with the critical thinking skills and subject knowledge typical of HE curricula. Thus, the definition used for an integrated curriculum was adapted from Cedefop (2010) "A document (or a collection of documents) and process providing the framework for developing and delivering learning experiences which matches learner and employer/labour market needs". In all the concepts and modalities of WBL, the main differentiating factor is the extent to which employers/practitioners influence the development and delivery of the curriculum. In any case, the important issue at this point is the necessary contact between theory and practice, wherever and whenever it takes place.

\section{People involved}

The third basic pillar in the framework consists of the people involved in planning and conducting the programme. This concerns all the agents directly involved in WBL: students, company tutors and academic staff; all the human resources. These people ultimately make the learning and the integration possible (Zabalza, 2011). The main difference from a traditional programme is the inclusion of strong relationships with people outside the HEI institution. For example, one of the Austrian cases mentioned that, "The integration of work-based learning into the curriculum is not the sole responsibility of the development team [...]. Members of the development teams are also invited to contact members of the study programme's overarching expert teams".

Students are the reason why the WBL programme exists. The success of the whole programme depends on how the programme is able to engage the students in work activities and make them learn about and through work activities (Billet, 2009 p.289). Tutors and academic staff, on the other hand, are the facilitators. Students need to be guided by expert practitioners. (Burke et al. 2009, p.30).

This initial approach made us aware that these pillars cannot work separately, as all three continuously interact. It is precisely this interaction which makes the difference, insofar as it enables better learning. That is, the quality of this interaction should mark the difference between a practice and a good practice in a WBL programme.

\section{Defining the interactions}


In building the new framework, the second group of elements required must be specifically related to the provision of learning opportunities and how they were considered at all the organizational stages of the development cycle. All these elements are reported in the WBL literature, but they have never been combined in the same framework. They appeared when the students' learning opportunities were placed at the centre of the initial framework and the cases were reviewed from that perspective. From this viewpoint, we saw that the basic pillars do not work in isolation, but in combination. In other words, we are dealing here with the interaction between the basic pillars (see Figure 3). The figure shows that learning is at its highest when the intersections are maximized; thus, we have to pay special attention to these intersections in order to build an optimal WBL programme. It is here that good practices can be identified, as the balance between the pillars increases the programme quality.

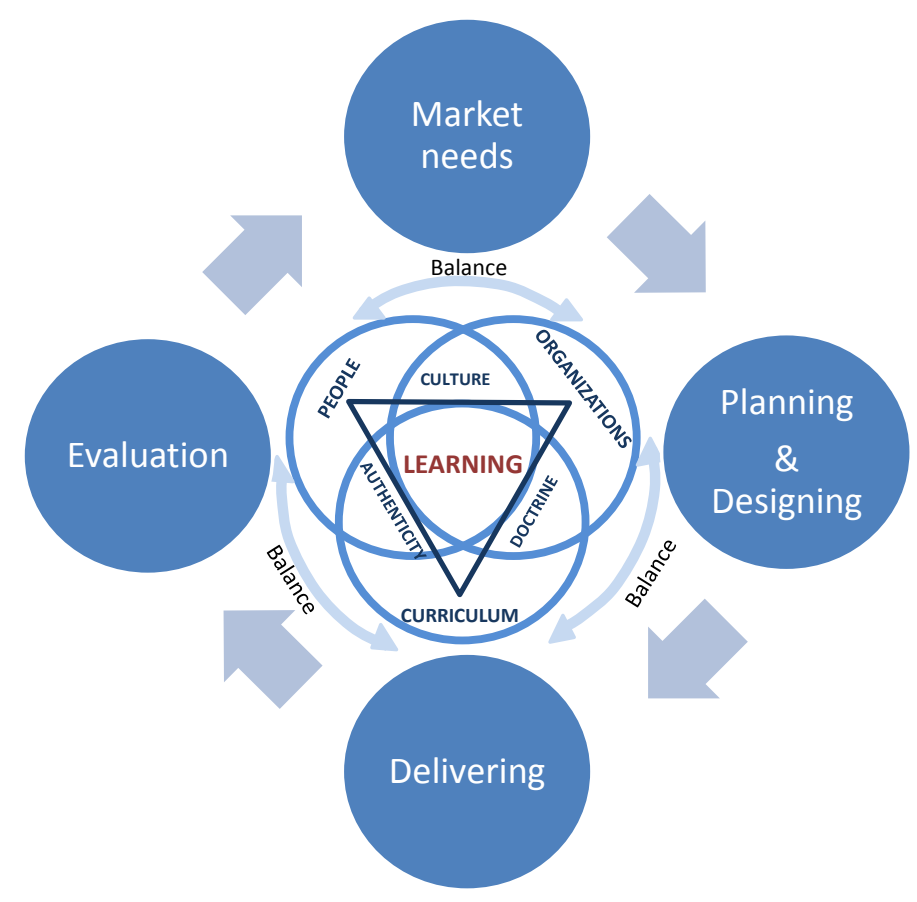

Figure 3. Conceptual Framework, Basic Pillars and Intersections between them

The first interaction takes place between the Organizations and the Programme. We call this interaction Doctrine. It refers to the importance of always remembering the main goal of the programme: to maximize the students' learning opportunities (Zabalza, 2004). In order to define a good practice the emphasis on these two basic pillars should be balanced. If this is not the case too much importance may be placed on the programme plan (forgetting the market needs) as often happens in traditional programmes, or too much emphasis is given to the organization's needs (forgetting the student's needs) as 
can happen when a company, for example, only participates in a programme for reasons of self-promotion.

Authenticity should characterise the interaction between Programme and People. Students should be provided with a real work environment, and given "real-world" work to do (Smith, 2011, p. 250). Tutors play a key role in ensuring the authenticity of the assessed work (McEwen et al. 2010 p.72). Threats that could unbalance the programme in this interaction include either over-emphasising the programme details (forgetting the market and students' needs) or giving too much importance to the people, leading to excessive clientelism or academicism.

Culture is the 'glue' between Organization and People. It refers to the way in which people in the participating organizations adapt their identity and their way of working to the WBL programme (Felce, 2010). It also affects the way in which students learn their vocation (Billet, 2009 p. 829). The threat to the development of an integrated programme from an imbalance between these two pillars lies, as above, either in too much emphasis on People (clientelism, academicism) or too much emphasis on the Organization (for example, leading into unnecessary bureaucracy or company-specific promotion).

\section{Towards a new Framework}

Having defined all the new elements in the framework, we now explain how they work in terms of studying good practice. To this end, we will follow the natural path of the development cycle (longitudinal methodology, Caïs, 2001). In this process, we will discuss where these new elements must be taken closely into account, and highlight the points of balance between pillars as the space for good practices. We also include some illustrative examples from our 14 cases.

Thus, starting with Market need, the Programme planning begins when Participating organizations make contact with each other. Through this contact the Programme is designed and it is in this product that the understanding of the student background (Doctrine) must prevail. This is followed by the delivery stage, where the academic staff, tutors and students (People) are the main resource. The Authenticity of experiences designed in the Programme depends on them, and they are essential for the success of a quality WBL programme. The last stage of the cycle, Evaluation, is carried out between the People involved, and this stage is the moment for reflection on how different expectations (Culture) have been met in the programme. The Participating organizations meet again and, taking into account the voices of the stakeholders, they implement the improvements. At the same time, this Culture is integral to the Participating organizations, so it influences the planning and designing stages.

\section{Market need}

As stated above, market need should be what drives WBL. In other words, a recognized lack of skills or competencies has to be detected in the labour market. This lack of skills 
is reported either by potential students (People) who need to enhance their qualifications, or by employers (Participating organizations). It makes sense to identify any HEI efforts towards that goal as a good practice. Thus, we have an example of good practice of market need detection from the People pillar: the Austrian Production Technology and Organization Programme was developed because a potential market for this type of course was identified from the interactions between academics and members of industry already working in the area. Market need can also be detected by the Participating organizations. One example of this is the Spanish case of the Master in Innovation, where the Valencian Business Confederation identified the need to create a postgraduate programme to cover the growing need for innovation in the Valencian business sector.

\section{Participating organizations: between Market need and Programme Planning.}

Once market needs are perceived or observed, the labour market typically asks the HEI to develop an education programme to meet that need. However, in WBL, the HEI cannot develop the solution on its own; it needs an external organization (employer, intermediary, or social partner representing the interests of a group of employers) as a partner in planning the learning activities that will satisfy those needs. Thus, good practices will appear when such a partnership is established and maintained to develop a joint viewpoint from interaction to integration (Whittington and Ferrández-Berrueco, 2007). Some examples are reported from the undergraduate Business Studies case in Finland: "Every department has a discussion forum where the department staff meets a selection of company representatives from the region and discusses their needs and future plans. Simultaneously, the employees of the university can air their ideas on course development with the corporate partners". Another example comes from Spain (in the field of Industrial Engineering) "At the beginning of the course year, the person in charge of external relations for the programme contacts local companies in order to ask about their training and staff needs".

\section{Between Organizations and Programme (Doctrine): designing the programme}

Although all the parties involved benefit in some way from working together (Whittington and Ferrández-Berrueco, 2007), the programmes must be designed to maximize students' learning opportunities (Zabalza, 2004, Nixon et al. 2006). This is the idea behind the concept of doctrine. It is not always easy to achieve, however. Companies have other goals and must perceive a clear advantage or benefit, otherwise they will not become fully involved. A good example of this comes from a German case: "A prerequisite of the employers is that work cannot be neglected; for as much as the employers are interested in training their staff with the ultimate motive of raising loyalty to the company, they are equally unwilling to cut working hours. The most important challenge for the planning was thus to keep the workload manageable for the students and compliant enough to satisfy the recognition standards". One of the Finnish cases 
reports a solution to this question in finding mutual benefit from the collaboration: "The students can apply theory to companies' problems, and the university can also help with, for example, market research or product development, especially in SMEs".

How can learning opportunities be enhanced in the programme design? WBL is learning for work, at work, and through work (Brennan and Little, 1996 in Burke, 2009 p17). But not everything has to be learnt at work; theory is also important (Brennan and Little, 1996, in Burke, et al. 2009 p.17). At this point the guidelines agreed in the previous phase are put down in writing; the employer and the HEI should also be fully integrated at this stage, and this integration can now be transferred into the programme contents and approach. As partners in designing the programme, employers should feel they are also partners in really helping the student. In this way, the programme could also better meet the employers' needs (McEwen et al. 2010, p.74).

Billet (2009, p.840) describes an important issue to be taken into account in this stage. He states that the team should, firstly, "identify and acknowledge the pedagogic potential of practice experiences, and consider how these can be engaged and integrated within higher education curriculum to maximise students' learning experiences". Related to this, in one of the Austrian cases, (social work) students are expected to complete three practical work-life periods throughout their studies. These practical periods should all take place in different institutions, but ideally also in three different fields of social work, to enable students to gain a more holistic experience of the different circumstances of real-life social work.

Secondly, and again according to Billet, the team should include in the programme considerations on the nature of higher education, "and how best to prepare for, position, sequence, and identify the most appropriate duration of practice experiences, as well as consider support for learning from those practice experiences in such higher education" (Billet, 2009, p.840). As an illustration, a case from the UK (health care) was especially designed as a flexible programme. The programme needed to be co-created anew each time it was run. Flexibility had to be built in to accommodate new content according to the context demands of each cohort.

Thirdly, Billet (2009, p.840) states that the team must "identify what kinds of experiences might best develop, sustain and utilize students' personal epistemologies, including their critical engagement and reflection". In another UK case, for instance, "The programme overall has great flexibility in allowing the students to shape the assignments to support an area that is of particular interest to them".

We now report some important key points identified in the case studies to be taken into account in designing the programme, based on the concept of doctrine. Alignment of teaching and learning activities (Smith, 2011) means that the activities in the practice programme must be deliberately designed and connected to the theory and vice-versa. For instance, in one of the Spanish cases, "integration is evident [...] as most of the practical work which the student has to carry out during the Masters is integrated into the real role of the student as a professional in the company". Or, as in another case from 
Finland, "When the company sees that they have a task that suits any of the courses, and after the teacher has accepted the task as suitable for the theory that is the goal of the course, the company and the Company Clinic coordinator (on behalf of the university) sign an agreement for the task to be solved by the students in the class".

The effort required to enrich learning is likely to be more prominent among the student's interests than efforts involved in simply reviewing theory. No learning activity is likely to be productive unless the learning individuals find meaning in the occupation that they are learning and/or practicing (Billet, 2009, p.831). Furthermore, the students, tutors and academic staff are concerned to integrate the theory learnt in the university with the practice at the workplace (McEwen et al. 2010 p.76). One programme in Austria has a 'practicum accompanying course' that integrates work- and course-based learning. This course is delivered to small groups of approximately 10-12 students, and is designed to help students reflect between practical phases and theoretical knowledge. Another interesting example can be found in the Business programme in Finland: "the practical problem solving is included in numerous courses, and the description of what kind of practical tasks can be done in these is formulated in 'product cards' that the coordinator gives to companies during her visits, so they know what (and when during the academic year) kind of tasks they can suggest".

Assessment with integrative learning objectives. The integrative learning outcomes are the key objectives (Smith, 2011, p.259) of WBL; assessment should therefore be aligned with integrative activities. HEI teachers consider that for students to obtain the most value, they must be able to link theory and practice and integrate work undertaken at university with their work in the employer's organization (McEwen et al. 2010 p.74). For instance, in an engineering programme in Austria, "Module coordinators are responsible for bringing all teachers of the module and all groups together in order to create exams, wherein all knowledge and experience covered by the module can be assessed. These forms of coordination are especially relevant for all teachers, to create a basic understanding of which topics should be covered within all modules and all groups".

The literature highlights the importance of agreement between academic and practitioner assessors on the standards for assessment, so that they reflect the levels of student achievement within the WBL context. These assessors may include external examiners who operate outside what McEwen et al. call "the tripartite relationship of student, employer and HEI staff" (McEwen et al. 2010 p.71). Many examples found in the case studies highlight this point. For instance, in the Spanish Master in Innovation "There is an Advisory Board. It is an expert team coming from different areas related to business development. They have to advise the student in the project planning and execution in those areas directly related to their expertise area; to regularly assess the project progress and the assessment of the Master."

Some authors have suggested that academics may not be familiar with the day-to-day reality of the work context, which calls into question the validity of their assessment (Brennan and Little, 1996 in McEwen et al. 2010 p.72). Typical examples of bad practices 
reported in the WBL literature include inadequate guidelines, unclear goals and lack of detail about standard requirements (Webber, 2005, p.384 in McEwen et al. 2010 p.72). There is also evidence of the need for company tutors' engagement. When employers are engaged in the assessment process, their role tends to be central in mentoring students on the technical aspects of work-based projects and providing feedback to the academic staff on the students' performance (Nixon et al, 2006, p.43). HEI staff should also involve the company tutors in encouraging students to reflect in the workplace (McEwen et al. 2010, p.69). A good practice related to this is reported from a case in Austria where, "tutors on these reflexive courses are obliged to hold an exam for supervision themselves; the main objective is that these teachers accompany students during the practical phases and are the main contact point if questions or problems arise. This aspect of quality and personal development is crucial for students' practical integration". One way to combine learning and evaluation is through 'live' projects (McEwen et al. 2010 p.76). Examples of this were also found, as seen in the following comment from a Spanish programme manager: "On the placement, the student has to develop real projects (one of them is the final project) in order to put the knowledge into practice and cement the professional skills".

\section{From programme design to delivery}

Work-based learning especially requires integration between theory and practice. In WBL, any programme is something learners experience as an invitation to change (Billet, 2009 , p.835). Despite the clear practical scope and the focus on the workplace in the programme, it is dangerous to forget about the theoretical contents. If this happens the programme simply becomes a reproductive procedure closer to company training sessions than an HEI programme. A good practice in this sense was reported in Austria: "Courses of practical exercises are therefore always offered in parallel with traditional lectures, especially in any applied field".

\section{Delivering the programme: between Programme content and People (Authenticity)}

Work-based learning must take place in real, or at least well-replicated, work situations. Practice settings offer a range of experiences that are authentic in terms of acting out an occupation in particular work situations (Billet, 2009, p.838). Some key strengths of learning through workplace experiences are, (a) access to authentic work activities; (b) observation and listening; (c) access to more experienced co-workers; and (d) practice (Billet, 2009, p.837).

To enhance the effect of this Authenticity some considerations must be taken into account to safeguard the balance between Programme and People. Firstly, experiences, although real, are not learnt in the same way. Learning depends on previous experiences. Consequently it is important to consider both the provision of experiences and individuals' take-up of those experiences (Billet, 2009, p.835). In this vein, a UK 
programme manager reported the following good practice: "The philosophy of the programme is one of self-directed learning, allowing participants to explore areas of professional interest to develop evidenced based practice and new ways of thinking within the mobility sector"

Secondly, experiences are also goal-directed (Burke et al, 2009, p.24). This means that practice periods must be established to enable a previously planned objective to be learned. In one of the Spanish cases, "Once a term (that is 5-6 visits throughout the programme), the academic company tutor goes to the company in order to make an assessment along with the student and the company tutor. All three sign a document where the assessment and new objectives for the student are established".

Teachers or mentors are the learning mediators (Billet, 2009, p.838). The role of these actors is essential and widely recognized. An example from Germany illustrates this: "To ensure the flexibility of the programme in the study course "Prozesstechnik" the students are individually tutored at an intense level by their teachers, who are the normal FH or Academy teachers. In this way the students have the possibility to learn at their individual pace and level". In Austria, "Other learning support is provided through individual coaching for students; individual contact between teachers and students is encouraged at any time of the study programme”.

Assisting individuals in developing the capacities to realize their vocational ambitions includes understanding the goals for occupational preparation, as well as how integration of experiences in both academic and practice settings can contribute to generating occupational expertise (Billet, 2009, p.831). Here, a programme manager in Spain says that their "students have a personal tutor (Senior Advisor) who helps to solve any academic problems, as well as supervising all the work the student is going to undertake during the Master and supervising the Master Thesis."

People: a central element in the Delivery and Evaluation of the programme

On delivering a programme, a new element emerges, which we call People. This general term includes the students, company/employer tutors and academic staff. This does not mean that these stakeholders are not at all relevant in the previous stages, but we consider that their role in the earlier stages is more related to an organizational perspective. In the later stages of the programme, as "users", their roles are more evidently those of individuals. Good practices in this pillar are detected when all the programme actors are involved in delivering and evaluation.

Communication is related to accessibility (Smith, 2011). McEwen et al (2010, p. 79) noted that the three-way communication between the academic tutor, students, and the company/employer tutor is particularly important. A good example of this practice was found in Spain: "After this, the whole cohort (of students), led by the pedagogical tutor, negotiate and decide which competencies to work, how much time to spend on each one 
and the methodology (visits, seminars, etc.). There is a special budget for this. The analysis is individual, but the response is collective. Once the student is assigned to a company, this company, the HEI and the student together define the profile with the basic competencies required at the end of the programme. This profile becomes a learning contract and it is signed by the three parties".

Assessment is another stage in which all the agents must be involved. It must therefore obviously include the student (Doughty et al, 2006; Brennan and Little, 1996, Raelin, 2008). But the students and tutors need support from the HEI, and at least some kind of guidelines should be provided (McEwen et al. 2010 p.77). As some forms of assessment may be unfamiliar to individual tutors, their understanding would probably be largely premised on their own personal experiences of assessment (McEwen et al. 2010 p.75). One Spanish case resolved this issue as follows: "The company tutor is trained and is continuously supported by the HEI which facilitates the tutoring work and homogenizes objectives and assessment criteria". In Austria, we detected a similar solution: "Worklife tutors do receive specific documents, which state what students should learn and experience in their practical phases and how the practical phases are integrated into the study programme".

Between People and Organizations (Culture): reflection and improvement

In our framework, culture is the intersection between People and Participating organizations. People behave differently depending on context, habits, expectations, and so on. In this way, this intersection to a certain degree determines the specific behaviour of an organization. Different cultures will produce different results in terms of reflection and improvement. For example, McEwen et al. (2010) found concern among academic staff "that employers would have neither sufficient time nor knowledge about 'critical reflection' to encourage it among students. [...] some employers consider that it was the role of the university to develop skills of reflection in students, but with their support" (McEwen et al. 2010 p.69). Some practices therefore attempt to solve this problem by training company tutors in the skill of critical reflection. Sometimes critical reflection is mainly carried out by the HEI, as in the following response from Spain: "Once a month students spend three days a week in the HEI and only two in the company. These are reflection days, and they are used to talk and share experiences".

More closely related to the beginning of the cycle are Induction and preparation processes (Smith, 2011). These processes help prepare students culturally for the work ahead (in a pedagogical and a practical sense), dealing with the student allocation, documentation, building relationships with industry partners, etc. The following practical examples were reported in Austria: "The preparatory and debriefing phases are very important for those students who will travel abroad, and are much more so than for those who will remain in Austria. They deal with intercultural differences that may arise, as well as main problematic areas in the target regions (typical diseases and their treatment or pre-immunization, how to deal with critical situations, how to handle impressions of 
total poverty, etc.). De-briefing then also means content-wise de-briefing (reflection on what was done in practice) and organizational feedback (possibilities to enhance the information provided before the stay abroad)". A UK programme reported: "This module [Skills and Approaches for Work Based Learning] is designed to help prepare the ground for work-based experiential learning and the accumulation of academic credit for this purpose. It usually follows the Self Review module".

The Coordinator's role is to oversee the programme, to support company tutors and students in a company and to build the culture of 'public space' (Harris et al. 2010, p. 553). This is illustrated in an example from Spain: "The Academic Coordinator is the person in charge of coordinating the teaching team as well as all the professionals taking part in the programme (tutors in companies, invited speakers, etc.). He/she also coordinates the Principal Advisor team and the Advisory Board in order to guarantee the normal development, monitoring and assessment of the modules". Company tutor's training sessions facilitate and ensure a better learning experience and provide staff with information and guidelines on academic requirements (Harris et al. 2010, p. 554). This is especially important when students from the cohort are all undertaking WBL in different workplaces (McEwen et al. 2010 p.71, Zabalza, 2011). This is illustrated by a practice in the UK: "The tutor team comprises experienced practitioners within the sector and every tutor completes additional training to ensure they can offer appropriate academic guidance and support to learners".

Working in the 'public' and 'private' space (Harris et al. 2010) is difficult because students can challenge the efficacy or even the appropriateness of the learning experience in a 'private space'. In other words, it is sometimes seen as inappropriate for experienced employees to allow students to critique or challenge their culture or practices. This issue was illustrated in a case from the UK: "The fact that the HEI have a sound understanding of workplace learning in terms of the pressures it puts on employees/students and the codelivery organizations, as well as an understanding of the notion of 'reflexive practice' and how that fits, is key. Such an approach works well in terms of workplace learning since it forces the employee/student to consider what they are learning in the context of their daily activities in the workplace. Companies and universities have their own learning support structures". Integrating these structures may help to alleviate the stress and/or improve the learning process (Smith, 2011, p.252). This is the structural capital, and it has to do with the combination of all the organizational and human resources in order to foster and facilitate learning among all the parties (Felce, 2010). We refer to one of our cases from Germany, where all learning resources are provided by the FH Aachen or the Academy, and the employers usually provide working hours and the technical requirements such as plant or laboratories. Another programme reported the following from Austria: 'Some 'bridge courses' are offered in subjects with complex theoretical content before the official start of the study programme, and many students (especially those who are older than the average student) use them to 'get back into a studying and learning mode'. [...] Another important form of learning support relates to preparation for exams. If some students approach course lecturers or the study 
programme leader, and state that they need additional support in preparation for exams, usually supportive courses are offered as consequence”.

Students' Engagement, according to Billet, "is related to how students engage with and learn through what they are afforded" (Billet, 2009, p.831, Raelin, p.18). There is a need to focus on preparing students as "agentic learners" as part of their professional preparation (Billet, 2009, p.838). An example from the UK illustrates this point: "a Self Review and Negotiation of Learning module requires students to engage in a process of personal review and then negotiate an outline learning pathway ('approved studies') based on their personal and professional development needs. This is typically the first module a student will take on their WBIS study route, enabling them to engage in the process of programme planning, typically including the formulation of a claim for the accreditation of prior learning".

The value and benefit of a learning community lies in the way it enables students to develop their own self-supporting groups. (Harris et al, 2010, p.550). In Austria, this result was obtained in the following way: "At this point it became clear that learning, or the development of knowledge and know-how during the study programme, is provided not only through lectures and traditional teaching methods, but also by the exchange of experiences between students. The programme had to be designed to allow space for this kind of interaction, but which uses that exchange of experience to contribute to the learning of the whole student group".

\section{Conclusions}

Higher education institutions should weave the workplace perspective into their education programmes in order to better match the needs of a changing society. Starting from the programme development cycle for work-based learning (WBL) programmes, the aim of this paper was to build a new framework that would go deeper in identifying the basic elements that reveal best practices in order to develop a good WBL programme with learning as its central goal. In this article, the framework was completed with case studies from 14 best-practice work-based learning programmes.

In all the cases reported, university and labour market have worked together in a partnership. Depending on many contextual factors (tradition, regulations, flexibility, etc.) this partnership was more or less integrated, but all the cases we found evidence of some elements that highlighted WBL as the main strategy in the curriculum design, delivery and evaluation. These elements were the ' 3 Ps', Participating organizations, People involved, and Programme structure. This seems to hold no matter what kind of higher education system the WBL experiment is linked to, at least on a European scale.

Nevertheless, although these elements were always present, there were clear differences in the cases that reveal varying levels of curriculum integration. Hence, while we can say they were WBL experiences, we are not able to conclude which ones are better in terms of students' learning opportunities (Brennan and Little, 1996, Raelin, 2008) or 
significance (Garnett, 2005). In other words, how can a "practice" be distinguished from a "good practice" in WBLIC?

Our proposal to answer that question is based on the balance between the common principles, as an unbalanced treatment would expose other goals apart from those providing the best learning opportunities.

While it is important to follow a standard process for good programme planning and conduct, it is of equal importance to strike a balance between both internal (HEI) and external (employer) organizations, the students, teachers and tutors, and the programme's theoretical and practice-based content. Thus, the framework is completed with mechanisms that bridge the gaps between these ' 3 Ps'. These mechanisms are the differences in the Culture, the Authenticity of the programme activities, and the Doctrine that programmes have in order to maximize the learning opportunities for students. Although they have been previously reported in the literature and there is clear evidence of their value in the students' learning, they never have been combined in a single framework. This new framework aims to bring them together to provide an instrument that informs decision makers on the best strategies (best practices) to use when designing a programme based on WBL from Garnett's (2005) perspective.

In spite of the different educational systems and contextual variations among the countries involved, there is ample evidence in the practices reported that all the elements identified in this article are indeed critical to and common to all the cases reported. That does not mean that all the practices are fully interchangeable among countries. For example, some organizational decisions cannot be made in all the cases, as regulations prevent their application. But many others can be, especially those related to pedagogical decisions. The next stages will lead us to discuss what is and what is not applicable in different contexts.

This research has certain limitations. First, the cases are all European, and they may be culturally biased. They were also selected by a few individuals at a national level, which may introduce another bias. However, we have attempted to cover, at least partially, the most important higher education system ideal types in Europe: the British WBL tradition, the Fachhochschule system, the Southern-European traditional universities, and the PostCommunist systems. This is naturally a narrow selection, but nonetheless case studies are a good way to bring forth new theories or frameworks, although they cannot provide statistically significant conclusive evidence on these theories. This report must therefore be seen as a proposal, rather than a definite statement, on what makes a good work-based learning programme in universities. Therefore, while we are proud of these results, we aim to continue the research on a larger sample and taking a more decisive research approach. 


\section{References}

Billet, S. (2009): Realizing the educational worth of integrating work experiences in higher education. Studies in Higher Education, 34 (7), (827-843).

Brennan, J. and Little, B. (1996) A review of Work-based learning in Higher Education. Sheffield; Department for Education and Employment.

Bruges Communiqué (2011) Supporting vocational education and training in Europe. Luxembourg: Publications office of the European Union. (http://ec.europa.eu/education/library/publications/2011/bruges_en.pdf)

Bucharest Communiqué (2012) Making the Most of Our Potential: Consolidating the European Higher Education Area. EHEA Ministerial Conference.(http://www.ehea.info/Uploads/(1)/Bucharest\%20Communique\%202012(2) .pdf)

Burke, L.; Marks-Maran, D.J.; Ooms, A.; Webb, M. and Cooper, D. (2009) Towards a pedagogy of work-based-learning: perceptions of work-based-learning in foundation degrees. Journal of Vocational Education \& Training, 61 (1), (15-33).

Caïs, J. (1997) Metodología del análisis comparativo. Volume 21 of Cuadernos Metodológicos, Centro de Investigaciones Sociológicas (Madrid).

Cedefop (2010) Learning outcomes approaches in VET curricula: a comparative analysis of nine European countries. Luxembourg. Publications Office http://www.cedefop.europa.eu/EN/Files/5506_en.pdf

Cedefop (2013) Benefits of vocational education and training in Europe for people, organisations and countries. Luxembourg: Publications office. http://www.cedefop.europa.eu/EN/Files/4121_en.pdf

Contreras, J, (1991) Enseñanza, Curriculum y Profesorado. Madrid: Akal

Creswell, J.W. (2003) Research Design. Qualitative, Quantitative, and Mixed Methods Approaches. $2^{\text {nd }}$ Edition. London. Sage Publications.

Deming, W.E. (1982) Quality, Productivity and Competitive position. Cambridge, MA. MIT University Press. Cambridge, MA.

Doughty, R.; Harris, T and Mclean, M. (2006) Tripartite assessment of learners during practice placements in midwifery pre-registration programmes. In S. Roodhouse, M. Bowley and S. Brown (Eds.) Putting Work-based learning into practice, Proceedings of the University Vocational Awards Council Annual Conference, York, November.

EC (2012) Bologna Implementation Report. Retrieved from http://www.ehea.info/Uploads/(1)/Bologna\%20Process\%20Implementation\%20Report. pdf (last retrieved on 20 February, 2015) 
Felce, A. (2010) Towards a Context-engaged Approach to Work-based Learning. Learning and Teaching in Higher Education, Issue 4-1,(20-35)

Ferrández-Berrueco, R. and Kekäle, T. (2014) Relationship Between Labour Market and University. Work-Based Learning Experiences in Europe. ICERI2014 proceedings. Seville, November.

Garnett, J. (2005): University Work Based Learning and the Knowledge Driven Project in Rounce, K. and Workman, B. (Eds.): Work Based Learning in Healthcare. Chichester: Kingsham

Garnett, J., Workman, B., Beadsmore, A. and Bezencenet, S. (2008) Developing the structural capital of higher education systems to support work-based learning programmes in Work-based learning: Workforce development: Connections, frameworks and processes . York. The Higher Education Academy.

Glatthorn, A.A. (1985) Case study: An overview of One Kind of Research, University of Pennsylvania, PA.

Harris, L.; Jones, M. and Coutts, S. (2010) Partnership and learning communities in workintegrated learning: designing a community services student placement programme. Higher Education Research \& Development, 29 (5), (547-559).

Helle, L.; Tynjälä, P. and Olkinuora, E. (2006) Project-Based Learning in Post-secondary Education - Theory, Practice and Rubber Slingshots. Higher Education 51 (287-314)

Mcewen, L.; O’Connor, K. M.; Williams, C and Higson, H. (2010) Engaging employers as partners in work-based learning assessment: proposal for a quality enhancement framework. Learning and Teaching in Higher Education, 4 (2), (62-89).

Nixon, I.; Smith, K.; Stafford, R. and Camm, S. (2006) Work-based learning: illuminating the higher education landscape. The Higher Education Academy. Final Report. (Retrieved from: http://www.jisctechdis.ac.uk/assets/was\%20York\%20\%20delete\%20this\%20soon/documents/ourwork/tla/web0597_work_based_learning_ill uminating the higher_education_landscape.pdf last retrieved on 20 February, 2015)

Nowotny, H.; Scott, P. and Gibbons, M. (2001) Re-Thinking Science: Knowledge and the Public in an Age of Uncertainty. Polity, Cambridge, UK.

Patton, M.Q. (1990) Qualitative Evaluation and Research Methods. Newbury Park, CA. Sage.

Raelin, J.A. (2008) Work-based learning; bridging knowledge and action in the workplace. San Francisco. Jossey-Bass

Smith, C. (2012) Evaluating the quality of work-integrated learning curricula: a comprehensive framework. Higher Education Research \& Development. Vol. 31, No. 2, (247-262) 
Stewart, T.A. (1997) Intellectual Capital: The New Wealth of Organizations. New York. Doubleday

Webber, R. (2005) Integrating work-based and academic learning in international and crosscultural settings. Journal of Education and Work. 18 (4), (473-487)

Tranfield, D. and Starkey, K. (1998), The nature, social organization and promotion of management research: towards policy, British Journal of Management, 9, pp. 341-53

Willis, P. and McKie, D. (2011) Outsourcing public relations pedagogy: Lessons from innovation, management futures, and stakeholder participation. Public Relations Review, 37 (5), pp. 466-469.

Whittington, B. and Ferrandez-Berrueco, R. (2007) From Interaction to Integration: Developing the Relationship Between Higher Education and the Labour Market. In Baugmartl, B.; Mizikaci, F. and Owen, D. (Eds.): From Here to There: Mileposts of European Higher Education. Vienna.

Zabalza, M. (2004) Condiciones para el desarrollo del practicum. Profesorado: revista de currículum y formación del profesorado, 8 (2), (1-22).

Zabalza, M. (2011) Actividad tutorial en el practicum. Revisión de la literatura. Revista de Educación, 354 (1), (127-154). 